\title{
Selected Methods of Psychological Manipulation in the Marketing of Financial Services
}

\section{Sylwia Lach}

Doctoral student in the Academic Subunit for Organizational Sociology and Business History Faculty of Management University of Warsaw, Poland

\begin{tabular}{|l|l|}
\hline & ABSTRACT \\
\hline $\begin{array}{l}\text { 2016 Research Leap/Inovatus Services Ltd. } \\
\text { All rights reserved. }\end{array}$ & $\begin{array}{l}\text { The main purpose of this article is preliminary identification of manipulation techniques and } \\
\text { methods used in banks for staff relationship management. The empirical contribution of this } \\
\text { article is to discuss the influence of immediate supervisor on the consumer's consultants in the } \\
\text { banking sector. The author has tried to answer the research questions, Are there any } \\
\text { manipulation techniques used by bank managers? If, yes, what methods of psychological } \\
\text { 8558.2015.61.3004 } \\
\text { manipulations are applied by supervisors on to their employees. Data is gathered by using } \\
\text { Keywords: }\end{array} \quad \begin{array}{l}\text { interviews with an experts' group and by the critical reflection on the professional experiences } \\
\text { of the author of the article. The initial results highlight some manipulation techniques used by } \\
\text { bank managers on the consumers' consultant, for example, the reciprocity technique, group } \\
\text { Manipulation techniques, Persuasion }\end{array}$ \\
$\begin{array}{l}\text { technique, the contrast technique, authority technique, word manipulation technique, } \\
\text { impression management technique and social manipulation techniques, such as the foot-in-the- } \\
\text { mouth and dialogue, the door-in-the-face", stressful situations, feelings of guilt. It is also worth } \\
\text { noting that in opposition to techniques there are examples of psychological counteraction to } \\
\text { manipulation, for example, the instinct to restrain aggression and empathy, change assessment } \\
\text { into opinion, violation of the principle of reciprocity, self-esteem, personality and manipulation. } \\
\text { The author also paid considerable attention to aspects such as rights and needs of the employee } \\
\text { in the sales of financial services and his job satisfaction.. }\end{array}$ \\
\hline
\end{tabular}

\section{Introduction}

This article presents preliminary research on exploratory charter concerning psychomanipulation techniques in relations between supervisor and subordinate in the banking sector. For the purpose of this paper, by the term of »psychomanipulation« I understand this kind of social influence, which informally could be defined as a machinations, i.e. insidious acting on someone's detriment or subterfuge, i.e. unfair behavior, scam. It is therefore social influence based on scam, which its main goal is an harm of addressee of that influence (Witkowski 2000). As an harm I understand objective treatment of second man, which undermines values being protected in west culture by a Kant's categorical imperative. Hovewer,»manipulation techniques « are nothing more than practical ways of manipulating people, i.e. manipulator's workshop tool (Witkowski 2000). The social impact does not always have to be negative, as it also helps to motivate employees to work and achieve better results: Follett's opposition to domination did not make her a precursor of today's human relations camp, with its manipulative emphasis on recognition and praise aimed at making employees feel big enough to take on the company's problems (Hoopes, 2003 p.156) or dea of the manager as therapist with the accompanying temptation of psychological manipulation, his hyper fear of conflict, and his Utopian claim that the interests of employer and employee can be merged in a workplace where the principal reward is not money but organic community (Hoopes, 2003 p.191). Organizational culture is one of the most important aspects, as it covers the main issues that concern: symbolic and interpretative aspects of management, social game and interactions between organisational actors, organisation seen as the construction of social reality(Sulkowski, 2014 p.63), which provide the foundations for building proper interpersonal relations. Psychological manipulation is to some extent a contradiction of the literature's social impact, because the victim of manipulator does not fully act consciously when performing certain actions or making certain decisions: There are certain cases, it is argued, where agents are the victims of manipulation and are thereby intuitively not responsible for what they do, despite meeting compatibilist conditions on moral responsibility (King, 2013 p.65). What distinguishes psychomanipulation from other manifestations of social impact is the fact that it is a phenomenon strongly associated with negative evaluation. In the publishing market, especially when it comes to non-scientific literature, there are many textbooks or guides of manipulation, the content of which usually comes down to a description of how to effectively influence others. I think that in case of modern sales training, it can also be seen in this way. The subject discussed in this article is, of course, one of the wider topics of 
HRM in banking. However, the number of studies related to this issue, especially those which can be used as a background for the analysis of psychomanipulation techniques, is so far little. In this article I address detailed issue of the use of manipulation techniques by managers of sale institutions and direct sales directors to client advisors. Such a clarification of the subject was created due to my professional experience and the review of subject literature. On the one hand, during my five-year career in banking (2011-2016), I intuitively registered a number of behaviors of managers with characteristics of psychomanipulation. Especially the training I underwent was based on how to effectively sell a banking product to a client very often it turned out that sales techniques had an impact on the behavior in relations between employee and employer. As managers also took part in these trainings, one of examples can be the technique of authority, i.e. building in the eyes of others an impression of competent and therefore trustworthy person. It is aimed in case of client's advisor to build trust according to the client's needs (completion of sales transaction) and in case of supervisor - to build a position in the team, which will enable to efficiently manage the group. On the other hand, this topic has proved to be largely absent from the scientific publication charters. Generally speaking, interpersonal relations between»supervisor and employee« at the bank as the workplace, has so far been rather poorly developed in terms of research. Exceptions include the work of Alvensson Mats and Robertosn Maxine (2012). The article discusses identity issues in relation to older employees of the UK investment banking sector. The authors relied on collected materials and the survey showed doubts regarding the issue of identity or involvement in what is usually perceived as identity work. Instead, they confronted with an orientation towards minimalism of identity and potential challenges to their identity, i.e. to what had been conceptualized as teflonic identity manoeuvring. Respondents used material resources, in particular money, to rationalize their needs, including social needs (dress codes) and discursive resources (around professionalism), in order to strengthen and maintain their image. Relations of six people from professional life were presented. Sensitivity, emotions and personal investment in the values of work were not important in their professional history. It was not noticed that the surveyed persons identified themselves with institution in which they worked. The issue of manipulation also has an impact on identification with the workplace, how the work atmosphere is created, and the relation between employee and employer is also important. The use of manipulation in the relations between a client advisor and manager prevents full involvement in work that has any basis that is deeper than a material benefit. Mentioned studies by Mats Alvesson from Business Administration at Lund University and Maxine Robertson from Queen Mary University in London were conducted with unstructured method and were exploratory. My search, narrowed down to the issue of psychomanipulation in relations between supervisor and subordinate in the bank, follows this pattern. Responses to the research problem are used: What psychomanipulation methods do supervisors (sales manager, direct sales director) apply to their employees (client advisors) in the bank sector? Selection of the above positions of supervisors and subordinates resulted from the fact that according to the banking hierarchy, directly above the client's advisor was the manager of sales institution and the director of direct sales, who accounted his subordinates on the basis of sales plans resulting from implementation of a specific bank policy. These were persons who, through their duties, had contact with the client, which in turn resulted in a further impact on the adopted banking strategy. I sought answers to the previously formulated research problem through qualitative research, which was a combination of elements of the ethnographic interview method and autobiographical narrative interview method. Qualitative research was modelled on research methods in humanities management (Kostera, 2015). The elements that were taken into account for the ethnographic interview were time - important for the expert to be immediately after the end of his work, place - the location was to be free for the expert, lack of third parties so as not to influence the course of research, language of the interview to be comprehensible for the expert. During the autobiographical narrative interview, important aspects were the ability to self-observe of own experiences, so that they could be written down as a form of personal narration. Creation of a personal essay helped to deepen the understanding of the process taking place in a specific social context through embedding of an individual biography confronting the conducted interviews. A very important element was the order in which methods were applied (1) the autobiographical narrative interview, (2) ethnographic interview, as this allowed avoiding suggestions made by experts. In order to carry out the interviews I used the technique of judges and experts, which allowed me to investigate a complex problem, the quantitative measurement of which is difficult and sometimes impossible. The task of experts is to answer the questions, thus important is selection based on professional practice and the ability to think independently (no influence on the opinion of others, respect of own opinion). An important element is the independence of expert opinions, anonymity of courts, multistage character of the survey, lack of aversion to expressed opinion, and results obtained from the survey are presented by specialists in a specific field.

\section{Research}

\subsection{Exploratory Research on Psychomanipulation Techniques Applied to Subordinates by Bank Supervisors - Methodology and Conduct of Tests}

\subsubsection{Perationalization of Studied Phenomenon}

I have considered the narratives concerning these techniques contained in the statements of judges and experts during the qualitative interview as indicators of psychomanipulation techniques in the relations between supervisor and subordinate in the banking sector. It contained ten questions read to experts in random order for each of them. Questions concerned the following psychomanipulation techniques identified on the basis of subject literature, which in my opinion are based on the most 
universal behaviors and beliefs of people, among them are: reciprocity technique (Cialdini 2013), i.e. something for something, e.g. the supervisor, through seemingly selfless help, expects to repay; technique of authority (Cialdini 2013), i.e. building in the eyes of others recognition and competence; technique of verbal manipulation (Witkowski 2000), i.e. speaking between the lines, hiding important content for the recipient's consciousness; technique of impressions management (Witkowski 2010), i.e. building own image, e.g., as hard-working person by presenting the recipient with a history of achieved so far results; a foot in the door (Witkowski 2000), the request can be fulfilled if we precede it with another smaller request; stressful situations and inducing a sense of guilt (Witkowski 2000), creating a tense atmosphere and shifting responsibility onto others. During the research, apart from techniques which seemed to me to be obvious, it turned out that there were also other techniques which were not taken into account at the beginning and which emerged when analyzing the interviews of judge-experts. In addition to questions directly related to manipulation techniques, neutral questions not related to psychomanipulation (e.g. how was the day, how they feel) were used so that the conversation could run smoothly and the interviewed person did not feel uncomfortable. The expert statements were analyzed in terms of repetitive contents or similar meaning. In this way it was possible to obtain the common parts, which are characteristic for certain social impacts in the available literature. Techniques of psychomanipulation were analyzed and identified on the basis of dialogues between employee and immediate supervisor, as quoted by experts (examples in the further part of article).

\subsubsection{Characteristics of Judges - Experts}

Selection of judges - experts for this study was carried out according to the following criteria. They were employees of the banking sector on a position of sellers. People who work directly with clients are exposed to the influence of their managers, i.e. the management level. At the same time, direct contact with the client requires mental resilience. The work of seller with client is particularly complicated by the fact that sales plans are imposed from above and strictly enforced. These factors make the position of a seller conducive to the presence of psychomanipulation techniques on the part of supervisors, as they exert influence on the client in order to close the sales conversation, which will be the result of sale of a financial service and, consequently, development of sales plan. From the professional group - active sellers of banking products - I have chosen an expert group. It consisted of 8 people, aged 20-35, with relatively extensive experience working as a sales or in other positions in the bank. On average, the members of expert group had five years of professional experience in banking. Due to the socially sensitive subject matter of interviews, the fact that I asked about the characteristic behavior of both experts and their colleagues, the need to obtain the highest level of trust from the experts, I chose them in a deliberate way, among my friends. For the same reason, the experts will remain anonymous in this article. I will only reveal that the expert group has revealed common features which, in my opinion, are very important components in interpretation of results. Each of the experts started their professional careers during their studies, which may indicate early exposure to high stress from both the employer and university in terms of exams. The common element was the position taken (at the time of survey) as a client advisor with similar responsibilities and fulfilment of objectives set by the senior management in a form of sales plans.

\subsubsection{Research Plan}

The research was based on meetings and individual interviews with each of judges - experts, so that none of them could duplicate information already provided by others. Respondents had to feel freely and be confident that their sensitive data would be kept confidential at work. The comfort of conversation is very important, as the interviewed group was able to honestly talk about the relations between them and their immediate supervisor. All interviews were recorded and then written down for a more convenient analysis of collected information.

\subsubsection{Conduct of Tests}

Interviews were conducted over the months of October and December (20161), on a ground most comfortable for the person, i.e. at their home, because they felt most comfortable there. The interview was conducted after the work of judge expert, so that emotions that accompanied them during the day were fresh and most real.

\subsection{Psychomanipulation Techniques Applied to} Subordinates by Supervisors in a Bank - Results of Research The narrations of judges - experts, writing these words, compared with own professional experience, which was a kind of filter, both enriching and distorting the results in a way that

1 Due to the sensitivity of this subject matter, I publish it after two years. was difficult to control unambiguously. This is something that I leave to readers to judge. The narrations of experts revealed common factors that all were subject to in terms of motivating their supervisors to work: sales bonuses, which were a form of reward for their results in sales, effects from work, very often this aspect was emphasized after management meetings at higher levels, which was also connected with promotions and praise, job satisfaction, i.e. work of a client advisor was so profitable that they could count on, for example, a bonus recognised by the employer. It was also possible to identify demotivating factors, such as high sales plans, often beyond the employee's reach (client advisors), threats of dismissal, unpleasant comments, which are detrimental to the employee's welfare (e.g. you're completely useless, you are a hopeless seller, how did you managed to persuade your wife to marry when you cannot sell credit), requirement to compete between employees, as evidenced e.g. by the following quote: I don't need people to help each other. I am looking for people who will take out loans and clients - (expert A.) The experts 
emphasized that they achieve sales results at any cost, because the basic rate of their remuneration is not satisfactory and they want to take care of their mental condition so that the manager can not accuse them of anything, but in the opinion of supervisor, their efforts put in the work are still too small. The Bank (i.e. the manager) wants each of its employees to be the most profitable and effective.

Experts very often have sales training, which is encapsulated in top-down, imposed techniques. The employer tries to manipulate employees by putting pressure on them. Sales competitions enable experts to improve their qualifications and, as they say, to show up against the background of often thousands of people. Employees (experts) notice that they become victims of manipulation, but realizing this, they often turns out to be after the fact, that is after reaching the set goal by their supervisor. An additional point connecting the interviews was the character or rather the way of being a direct supervisor. Experts duplicated the statement that a manager always shows his superiority over his subordinates, e.g. I'm going to the HQ to meet managers, if someone calls please tell them that I will be tomorrow or don't discuss with me, because I'm in charge here trying to build their authority. Quite often, it turns out that an employer used threats in order to increase the effectiveness of employees, which further translates into the results of work. The expert group unanimously stated that although the employer is not the best, always takes responsibility when necessary, although there are exceptions. The manager strongly emphasized, I like to work here or since I'm here, the sales are getting better and better. The manager has also often tried to help, e.g. I'm also going to a photocopier, give me those papers I will be copied it for you or I can arrange everything for you, unless the President does not agree. Sometimes the direct supervisor had a short conversation with employee about a product rarely sold in order to confuse subordinate. These phenomena are illustrated by the following quotation from the relations between judges and experts: "Supervisor: it was you who managed to sell this bonus fund?; Adviser: yes; Supervisor: Oh... You're sure, Adviser: yes, what's the problem? Supervisor: Oh, well, but now it's up to you» (Expert B) Experts stressed that e.g. they knew that situation was quite difficult due to financial penalties received by the bank - they thought that they might not receive the promised discretionary bonuses. Then their supervisor said: All others were strongly instructed. We kept our face. However, you should be aware that the bonus may be very small. The surveyed group quoted in interviews a moment when the new employee was recruited and witnessed the manager turning to "new" employee: If you have any questions, please let me know or my colleague M. will show you exactly how our banking system works and will tell you about the procedures we have in place. Attention was paid not to force the rules from above and to do it in a very delicate way we are always at work at 8:30 a.m. to be able to start work calmly. Manager is very willing to help when, for example, it is necessary to call the department to discuss the details of transaction with the client or to negotiate appropriate terms of cooperation for the client. Persons from the expert group stated that very often their manager was trying not to use denials when asks for something or when wants to express own opinion. Additionally, they claim that in situations of increased sales they are more motivated by them, e.g. "K. try it really is not difficult and clients will like it very much, as you can be convincing" (expert C). Descriptions of the training provided by the supervisor clearly indicate that employees are to apply comparisons to products and offers of other banks. The sales effect will mainly depend on a way the offer is presented and how convincing they will be towards the customer. The statement has often been repeated: The client does not need to know that he needs it; we have to sell it in order for the Management Board to be satisfied, Me and you. Expert D. is a person who has been working in banking for 10 years. In his relation, my attention was drawn to what I experienced in my professional work, namely the direct supervisor during team meetings very often treated us impersonally, i.e. our sales met with great enthusiasm on the part of the Management Board quoted words by the expert show how the manager wants to assign individual merits to the whole team, so as not to exalt or reward anyone with recognition. It is a daily reality to raise a sense of doubt, but it is only about not being confident about yourself in order to be able to give in to your manager. The employer uses his position, for example, to carry out specific duties. In interview with expert E. - a very experienced advisor to wealthy client, I heard how the manager made a request to his subordinate, which required him to stay after hours to work out a loan application. This is illustrated by the following quote »Supervisor: A. I have to discuss with you, it's life and death; Adviser A.: Director, what happened?; Supervisor: At the last minute I received a loan application for consideration, could you tell me what the situation is like with our sale of credit volume? Tomorrow is the last day of month, maybe it could be somehow pulled up?; Adviser A.: Director, we are short on two credit applications of PLN 100 thousand to develop a sales plan this month. Supervisor: A. could you take a quick look at this application? If everything agreed, could sign it and I would take it to HQ tomorrow morning. Adviser: I'll handle it." (Expert E)

Expert (E). admitted that only after making his verbal declaration he understands that would not finish working quickly and that he would have to stay after hours to keep his promise. On the next occasion, he learned to distinguish between requests from which only the Director had a profit and those sincere intentions, and once again he did not agree to sacrifice the family for the work. During interviews, I heard quite often how the experts copied my experience of the situation, the employees were asking for an increase. It can be said that all experts unanimously presented the same situations of negotiations with their supervisors. The conversation took place on the ground of supervisor, i.e. in his office, if something had already been won, it was not as much as they would have expected - expert D. stressed that such negotiations coincided 
with the words a little win-win for both of us - he got a small penny and the supervisor was happy that much less than he could give. Negative stress situations are a common occurrence in a banker's work. All the experts told me how they were treated by their manager. They have heard many times that if they do not start selling their deposits, they can say goodbye to their work, because the Management Board will not maintain an unprofitable institution. In addition, the words such as I'm in charge here or Remember who is in charge here were on the border with mobbing. The experts emphasized that the Branch Manager held meetings to present the sales results of the team and very often they proved to be very close to goal at that time, with greater will and motivation, they tried to meet the tasks assigned to them. There were also situations when at meetings the supervisor emphasized how he had been treated by his supervisors for non-execution of a sale - expert B. said that everyone felt guilty for not realizing the plans. In such a situation, the whole team knew that they would be "punished" by lack of bonus. Experts claim that some of teams in which they worked had their own bootlicker, which went to their supervisor with every matter.Very often there were situations in which he was seen alone with the Director, as it turned out later that he benefited from it more in a form of higher discretionary bonuses. The supervisor always knew what was going on in the institution, and who with whom had certain relationships. Expert B. stated that in his professional career he always came across one type of manager, namely one who always said how it happened that became a manager, how his professional career was going and how much he did for his team. He often stressed that he was unable to check the deposit documentation due to more important duties. In addition, the frequent forcing of greater involvement in the work of experts was considered by their supervisors to be too small. Monday's meetings were aimed to discuss results, deliberate praise of people or humiliation of others introduced confusion and disorientation in the team and above all rivalry in the team.

\subsection{Summary of Results}

The narrative of experts-judges I asked leads to the following conclusions:

- The employer apply manipulative techniques to an employee that are used more or less skillfully,

- The employee is often unaware of used manipulation techniques,

- The employee who is aware of used manipulation is less susceptible to it, because is able to use innate defensive techniques against manipulation,

- Manipulation very often fades with threats and harassment on the part of employer, which is due to a lack of knowledge of the use of manipulation techniques by the direct supervisor.

- Pressure on sales, i.e. on results, puts more pressure on the employee, who is often stifled and intimidated.
My research shows - at the level of initial exploration - modern management personnel management of the lowest level in the banking hierarchy. Behavioral patterns duplicate and reflect actual work in the banking sector, of which the ordinary client will not be aware. The application of research techniques described above had both positive and negative sides. It enabled to get into the part of a banker, who in everyday professional life was doomed to chronic stress and sometimes mobbing. A limitation of research was the subjective evaluation of surveyed and their individual perception of certain behaviors and statements, which could have been presented in a completely different way by a third party. In the research there was no possibility of random selection, experts were colleges from work and universities, who were employees of the banking sector in very similar positions.

\section{Conclusion}

\subsection{Limitations to research work}

Conclusions for future research are to increase the research area and the expert group. As an extension of the issues studied by me, we should add individual relations between the clientemployee-employer, due to the position hierarchy and personal connections that may create relationships, which in conducted studies could not been captured. In the future, the issues of work should be extended to the following research areas: the use of manipulation in relations between client and client advisor, the use of manipulation in relations between manager and sales director, the use of manipulation in relations between sales director and bank's management, comparison of relations in terms of the frequency of manipulation between different bank structures. The sales relation and willingness of each party to make a profit has an impact on the sequences of behavior. An increase in the number of surveyed people would enable to study human behavior more closely and to draw more precise conclusions on the situation in operational institutions. An additional advantage would be the possibility to study the area of relations in the entire hierarchy of human resources management in the banking sector along with analysis of individual position connections, taking into account the emphasis on the lowest level, i.e. client advisors. To sum up, in the opinion of judges - experts, weaker units are unable to cope with the influence of third parties. People who are more selfconfident and mentally resistant to manipulation usually become perpetrators, i.e. manipulators. Influencing techniques are extended to managerial training, but also to client advisors who are expected to influence clients in this way. Contrary to appearances, despite their knowledge, they cannot defend themselves against manipulation because of fear and fear of losing their job

\section{References}

- Achtzigera, A., Alós-Ferrer, C., Wagner, A. (2018). Social preferences and self-control. Journal of Behavioral and Experimental Economics, 74, 161-166. Crossref 
- Alvesson, M., Robertson, M., (2015). Money Matters: Teflonic Identity Manoeuvring in the Investment Banking Sector. Organization Studies, 37(1), 7-34. Crossref

- Aronson, E., Robin, M. (2012). Social psychology. Profit and loss.

- Beck, G. (2007). Manual of manipulations prohibited rhetoric. Helion.

- Cialdini, R.B. (2013). Exerting influence on people. Theory and practice. GWP.

- Dolinski, D. (2005). Techniques of social impact. Scholar.

- Hoopes, J. (2003). FALSE PROPHETS The Gurus Who Created Modern Management and Why Their Ideas Are Bad for Business Today. Perseus Publishing.

- Johnson, C.L. (2003). Mafia manager. Machiavelli Corporate Manual. Book and Knowledge.

- Kaufman, B. (2014). The historical development of Americam HRM broadly viewed. Crossref

- Human Resource Management Review, 24(3), 196-218.

- Kostera, M. (2015). Research methods in humanities management. Sedno.

- King, M. (2013).The Problem with Manipulation. Ethics, An International Journal of Social, Political and Legal Philosophy, 124(1), 65-8. Crossref

- Kizińczuk, S. (2011). Techniques of manipulation. Words of Wisdom.

- Pietron-Pyszczek, A. (2007). Motivating employees. Marina Publishing House.

- Sulkowski, L.(2014). From Fundamentalistic to Pluralistic Epistemology of Organizational Culture. Journal of Critical Organisation Inquiry, 12(4), 59-77.

- Witkowski, T. (2000). Psychomanipulations. How to recognize them and how to deal with them. UNUS Moderator's Library Publishing House.

- Zimbardo, P.G., Ruch, F.L., (2002). Psychology and life. Scientific Edition of the Polish Academy of Sciences. 